\title{
KNOWLEDGE IS POWER: BEHAVIORAL ECONOMIC TOOLS FOR EMPOWERING CONSUMER DECISIONS
}

\author{
Arsh Agarwal \\ Modern School Barakhamba Road \\ DOI: 10.46609/IJSSER.2021.v06i05.018 URL: https://doi.org/10.46609/IJSSER.2021.v06i05.018
}

\begin{abstract}
The field of behavioral economics is being researched greatly, to understand the types of tools to influence consumer behavior in more positive and sustainable directions. It is apparent that individual choices and purchasing power have a great impact on the environment. An informed consumer base as well as a transparent manufacturing process is key to ensuring a sustainable and healthy economy. To remedy the situation of information asymmetry and ensure that both consumers and producers are acting in a sustainable manner, governments and stakeholders can collaborate to employ a myriad of behavioral economic tools. This paper aims to provide an overview of the various available tools and examine the theoretical foundations of behavioral economics. The paper then maps out the most effective tools to employ to encourage sustainable consumption, and provides the benefits, drawbacks and risks of employing different approaches. The paper then poses policy recommendations for the way forward to establish long term behavioral interventions to minimise risk and maximise transparency and impact.
\end{abstract}

\section{Introduction}

From both the perspectives of marketing and being a consumer, informed decisions about purchasing products hold great importance. The fields of behavioral analysis and behavioral economics have developed over the last three decades and examined the questions of what it means to be a responsible consumer, and how to improve consumer awareness about critical features in commercial product and service choice. Behavioral economics can provide valuable insights for marketers by helping them to identify behaviors and adapt to customers' irrational biases and emotional demands and needs (Skyword, 2020). Over the last two decades, the aspects of sustainability and fairness in the final product and in the process of manufacturing the product, have become important to consumers. On the other side of that coin, governments and policy makers are keen to change consumer behaviour to purchase more sustainable products and engage in practices which are better for the environment. While one part of this is to regulate the 


\section{International Journal of Social Science and Economic Research}

Volume:06, Issue:05 "May 2021"

products that companies are allowed to market, the field of influencing consumers and 'nudging' them in the right direction has been a topic of research interest.

What is important for research in the field to consider, is that while influencing consumer behaviour is key, it is equally important that consumers be made aware of all the information they need to make an informed choice. Encouraging sustainability throughout a business model and marketing the same to consumers has benefits for the business such as identifying new products and markets, leveraging emerging technologies, spurring innovation, driving organizational efficiency, and motivating and retaining employees (White et al, 2019). In addition, consumer demand for sustainable options, with $66 \%$ of consumers ( $73 \%$ of millennials) worldwide report being willing to pay extra for sustainable offerings (Nielson, 2015). However, researchers have noted that although consumers report that they would have a favorable attitude to pro-environmental and pro-sustainability behaviours and products, they often do not subsequently exercise their choices in a sustainable manner (Young et al, 2010). This discrepancy between what consumers say and the purchasing choices they make is a challenge for policy makers, marketers, and nonprofit organisations who are working to encourage sustainable consumption by nudging consumers in that direction (Johnstone and Tan, 2015).

This paper will examine the theoretical foundations of behavioural economic tools to influence consumer behaviour, and analyse the potential to improve and utilise the tools available to resolve the discrepancy between what consumers say and what they do. The paper will pose policy recommendations for marketers and public policy professionals to critically engage and employ these behavioral economic tools.

\section{Background}

There are several behavioral economic theories regarding the discrepancies in consumer behavior. George Akerl off in his classic 1970s article 'Markets for Lemons', examined the used car market and illustrated how the asymmetry of information between the seller and buyer could cause the market to collapse, getting rid of any opportunity for profitable exchange and leaving behind only poor quality products (Chen, 2020). The problem of information asymmetry arises when buyers and sellers have disparate amounts of information, which do not enable either party to make an informed decision about a given transaction (Chen, 2020). This difference between the perceived value of a product and its actual value, leaves behind only "lemons" or poor quality products. The same example can be applied in the case of influencing consumers to purchase sustainable products. Existing research on using behavioral economic tools to influence consumer choice has shown that consumers are sensitive to social abuse practices, unsustainable production methods and environmentally friendly products, but they face difficulties to access 


\section{International Journal of Social Science and Economic Research}

ISSN: $2455-8834$

Volume:06, Issue:05 "May 2021"

information in order to inform their decisions (Toussaint et al, 2021). In addition, nudging tools show that not all consumers behave the same way even in the same scenarios. For example, a study showed that when a meat based dish was served at large sustainability based events, only 5-10\% of diners would choose a vegetarian alternative. However, at the 2009 edition of the Behavior, Energy and Climate Change Conference, the organizers reversed the options and offered a vegetarian dish as the default option, and meat as an alternative (Rincon, 2020). Consequently, $80 \%$ of the 700 people who attended the conference opted for the vegetarian option (Rincon, 2020). The different presentation or formulation (framing) of the alternatives presented created the effect of a nudge and allowed customers to make the more sustainable choice, even though they were all ostensibly in favour of eco-friendly options.

Research on the intersection between behavioral economics and sustainable behaviors have found that the following factors most influence sustainable consumer choices - Firstly, social norms what is considered socially appropriate behaviour has a strong influence, for example, leading to actions like avoiding littering, selecting eco-friendly transportation, choosing sustainably sourced food, composing and recycling (White and Simpson, 2013; White et al, 2019). Secondly, social identities and a feeling of belonging within a likeminded group and being perceived as an environmentally conscious person by others has an influence, as well as being perceived as self-consistent such (Van der Werff, Steg and Keizer, 2013). Thirdly, consumers also tend to select sustainable options to make a positive impression on others, especially in public contexts (Green and Peloza, 2014). Research has also found that changing habits to more sustainable habits is easier achieved when the time taken to change it is reduced, and when the consumer is provided with incentives such as educating them about the benefits, and providing monetary incentives (White et al, 2019). Given this background, the following section of this paper will discuss potential tools to influence sustainable consumer choice, the potential risks and policy recommendations.

\section{Discussion}

Policy makers and markets must engage in an analysis of potential tools. including nudging tactics in order to present more sustainable consumer choices and more environmentally-friendly options. In doing so, it is paramount to recognise the importance of an informed consumer base for global markets and economies, to stimulate demand, to prevent the production of low quality products, and to inform manufacturing processes including labour rights and prevent environmental damage. By tailoring tools to the above mentioned incentives and social perceptions, it is possible to bridge the gap between what consumers profess are their values, and what they do. Some other techniques are to (1) appeal to social proof, (2) appeal to the consumer's sense of loss aversion by educating about environmental risks, (3) establishing an 


\section{International Journal of Social Science and Economic Research}

Volume:06, Issue:05 "May 2021"

emotional connection with the product to create an endowment effect, (4) by setting a sustainable option as the default, pre set option, and (5) framing the context within which the consumer must make the purchase (Skyword, 2020). In the sustainable consumption domain, research also showed that simplicity-based interventions such as using traffic light signals 14 to indicate the water usage during a shower significantly reduced the effort to monitor water usage, shortened shower time, and increased water conservation (Reisch, 2017). Another effective example has been that of some utilities and energy companies including a happy face on the bill if the customer is using less energy than the average of their neighbours, graphically persuading consumers to keep doing things right. This comparative report makes people think more and makes them more proactive towards energy sustainability (Rincon, 2020).

The particular challenge with the concept of sustainability itself is that it is perceived by consumers to be abstract, with the outcomes not clearly measurable to convince consumers that their individual choice is capable of some tangible change (White, 2018). A good example of how this issue has been handled is the example of the campaign by Our Horizon, which is a nonprofit with a mandate to discourage gasoline consumption caused by driving automobiles. Our Horizon appealed to the consumer's sense of social acceptance by working with local governments to place warning labels on gas pumps. This served to reinforce the consumers' sense of social norms and sense of approval, as well as communicate the tangible benefit of reducing gasoline consumption (White et al, 2019). Governments would do well to address the status quo bias theory of behavioral economics, and setting sustainable options such as green electricity default to push consumers in the direction of making sustainable choices (Reisch, 2017). In fact, the power of default is so strong that even disclosing how default works to influence consumer decisions does not reduce the effect of default (Reisch, 2017).

With the use of behavioral economic tools comes the potential for risks, depending on who is employing them. Firstly, research in the field is unclear about the long term effects and their impact on mass change of consumer behaviour. Secondly, nudge interventions that are focused on appealing to emotion may cause undesirable emotional changes (Reisch, 2017) . For example moral licensing, is an effect where consumers may feel they are entitled to an unsustainable choice after making several healthy or environmentally friendly purchases or choices. The rebound effect is another negative outcome wherein an individual's unsustainable consumption might reduce, but the overall consumption does not due to intensified consumption of a sustainable choice (Reisch, 2017). For example, consumers may reduce CO2 emissions by driving a fuel efficient car, but if more consumers demand fuel efficient cars, it increases unsustainability in the manufacturing process. This paradoxical situation is once again a result of information asymmetry between buyers and sellers. Private players may simply appeal to a 


\section{International Journal of Social Science and Economic Research}

ISSN: $2455-8834$

Volume:06, Issue:05 "May 2021"

consumer's sense of emotion without actually implementing sustainability in the supply and value chain (Toussaint et al, 2021).

To remedy this, a higher investment in transparency instead of certifications is recommendable, as sometimes companies could be considered greenwashing. In this regard a number of opinion leaders, including retailers and wholesalers, unions, media, and governments, can play a key role to enhance awareness through information flows (Toussaint et al, 2021). In addition, appealing to "fear appeals" especially in the context of environmental damage and climate change or appealing to a sense of consumer guilt can lead to a sense of being unable to overcome the threat and can result in denial (O'Neill and Nicholson-Cole, 2009). Therefore, moderating emotional appeals and focusing more on educating the populace on what actions to take and the effects of individual actions are more likely to appeal to positive emotions have been observed to have a better effect on influencing consumer choice (White et al, 2019).

\section{Conclusion}

It is clear that in fields from health behaviour to pension saving, from investment decisions to food choice, from sustainable consumption to the design of warning signs, the empirical and theoretical insights of behavioral economics have become a cornerstone of understanding consumer behaviour (Reisch, 2017). In addressing the issue of influencing consumer behavior, it is pertinent to acknowledge that the lack of information on social issues remains, where environmental issues have predominated over social problems. The collaboration between trade unions, NGOs and media is important to address these problems and remedy such information asymmetry (Toussaint et al, 2021). The collaboration between governments, the industry and trade unions is also important to counterbalance powers in order to take actions from both conceptual and practical perspectives (Toussaint et al, 2021).

Policy makers must consider the potential risks and unintended side effects of the use of behavioral economic tools, and engage in research that is able to map out the long term effects of behavioral interventions. In order to formulate effective long term interventions to encourage sustainable consumer choice, it is important for all stakeholders along the value chain to develop sophisticated and transparent ways of tracking the $\mathrm{CO} 2$ footprint throughout the chain, and of accounting and managing accumulated carbon credits and taxes in real time (Rincon, 2017). Transparency is also key in the process of production and mandating that consumers be made aware of the processes employed throughout the value chain. This will allow for an investigation into the appropriate stimuli for consumer reactions. As a concluding note, it is also pertinent for all stakeholders to consider the ethical issues and the possible violations of individual sovereignty in using behavioral economic tools to influence consumer behavior. There must be 


\section{International Journal of Social Science and Economic Research}

ISSN: $2455-8834$

Volume:06, Issue:05 "May 2021"

empirically tested, socially and politically accepted and culturally sensitive standards for governance that influences consumer behavior (Reisch, 2017). Unwarranted intrusions and manipulations from the private sector must also be regulated.

\section{References}

Chen, J, and Scott, G, (2020), 'Lemons Problem", Investopedia, https://www.investopedia.com/terms/l/lemons-problem.asp

Green, T., and Peloza, J., (2014), "Finding the Right Shade of Green: The Effect of Advertising Appeal Type on Environmentally Friendly Consumption," Journal of Advertising, 43 (2), 12841.

Johnstone, M, and Tan, L (2015), “Exploring the Gap Between Consumers' Green Rhetoric and Purchasing Behaviour," Journal of Business Ethics, 132 (2), 311-28

Nielsen (2015), “Consumer Goods' Brands That Demonstrate Commitment to Sustainability Outperform Those That Don't", http:/www.nielsen.com/ca/en/press-room/2015/consumergoods-brands-that-demonstrate-commitment-to-sustainability-outperform.html.

O'Neill, S, and Nicholson-Cole, S, (2009), "Fear Won't Do It': Promoting Positive Engagement with Climate Change Through Visual and Iconic Representations," Science Communication, 30 (3), 355-79.

Reczek, R., Trudel, R, and White, K, (2018), "Focusing on the Forest or the Trees: How Abstract Versus Concrete Construal Level Predicts Responses to Eco-Friendly Products," Journal of Environmental Psychology, 57, 87-98.

Reisch, L. A., \& Zhao, M. (2017). Behavioural Economics, Consumer Behaviour, and Consumer Policy: State of the Art. Behavioural Public Policy, 1(2), 190-206. https://doi.org/10.1017/bpp.2017.1

Rincon, E (2017), 'Behavioral Economics and Sustainability', Digital Biz, https://www.digitalbizmagazine.com/behavioral-economics-and-sustainability/

Skyword, (2020), '8 Marketing Takeaways from Behavioral Economics', https://www.skyword.com/contentstandard/8-marketing-takeaways-from-behavioral-economics/

Toussaint, M, et al (2021), 'What about the consumer choice? The influence of social sustainability on consumer's purchasing behavior in the Food Value Chain', European Research 
on Management and Business Economics, Volume 27, Issue 1, https://doi.org/10.1016/j.iedeen.2020.100134.

Van der, Werff, L, Steg, E., and Keizer, K, (2013), "The Value of Environmental Self-Identity: The Relationship Between Biospheric Values, Environmental Self-Identity, and Environmental Preferences, Intentions, and Behaviour," Journal of Environmental Psychology, 34, 55-63.

White, K and Simpson, B. (2013), “When Do (and Don't) Normative Appeals Influence Sustainable Consumer Behaviors?” Journal of Marketing, 77 (2), 78-95.

Whitse, K et al, (2019), 'How to SHIFT Consumer Behaviors to be More Sustainable: A Literature Review and Guiding Framework', Journal of Marketing, https://journals.sagepub.com/doi/full/10.1177/0022242919825649\#

Young, W, et al, (2010), "Sustainable Consumption: Green Consumer Behaviour When Purchasing Products," Sustainable Development, 18 (1), 20-31. 